Çukurova Üniversitesi Mühendislik Mimarlık Fakültesi Dergisi, 29(2), ss. 1-12, Aralık 2014

Çukurova University Journal of the Faculty of Engineering and Architecture, 29(2), pp. 1-12, Aralk 2014

\title{
Farklı Duvar Malzemesi ve Yalıtım Uygulamalarının Isıl Davranışlarının Deneysel Olarak İncelenmesi
}

\author{
Filiz ŞENKAL SEZER ${ }^{* 1}$, Şükran DİLMAÇ ${ }^{2}$ \\ ${ }^{1}$ Uludağ Üniversitesi, Mimarlık Fakültesi,Mimarlık Bölümü, Bursa \\ ${ }^{2}$ ÇEVKAK, Istanbul \\ Geliş tarihi: 04.07.2014 Kabul tarihi: 27.10.2014
}

\section{Özet}

Bu çalışmada, 1lıman iklim şartlarındaki binaların ara kat kirişli döşemelerinin ısıl davranışı üzerinde duvar malzemesi ve yalıtımın etkisi araştırılmıştır. Bu amaçla kullanım halindeki binalar üzerinde gerçekleştirilen gerçek şartlar altındaki ölçüm değerleri esas alınmıştır. Değerlendirme amacıyla 5 farklı duvar kesiti seçilmiştir. Yalıtımsız tuğla duvar + kiriş, yalıtımsız gaz beton duvar + kiriş, yalıtımsız hafif tuğla duvar + kiriş, çift duvar arası yalıtımlı tuğla duvar + kiriş ve dışarıdan yalıtımlı EPS Katkılı beton blok duvar + kirişten oluşan kesitlerin ısıl davranışı, 5 adımda kapsamlı şekilde incelenmiştir. Bu adımlar; tüm ölçüm süresi içindeki genel davranışlar, tüm ölçümlerde duvar ve kiriş sıcaklıkları arasındaki farklar, kesit sıcaklıklarının değişimi, ortam ve yüzeylerde ölçülen minimum, ortalama ve maksimum sıcaklıkların değişimi, kiriş seviyesinde iletilen 1sı akısıdır. Elde edilen sonuçlar doğrultusunda, bu 5 farklı duvar kesitinin ara kat kirişli döşemelerin ısıl davranışı üzerindeki etkileri karşılaştırılmıştır.

Anahtar Kelimeler: Isı köprüsü, Isı yalıtım etkisi, Isıl davranış, Isı akısı, Yüzey sıcaklığı

\section{Experimental Study on the Effects of Wall Materials and Insulation Conditions on the Thermal Behavior}

\begin{abstract}
In this study, the effect of location of thermal insulation and the type of wall material on the thermal behavior of mezzanine floor beam-slab element sections of buildings under temperate climate condition was experimentally investigated. Thermal behaviors of mezzanine floor sections comprising of uninsulated brick wall + beam, un-insulated autoclaved aerated concrete wall + beam, un-insulated lightweight brick wall + beam, insulated cavity wall + beam and EPS added concrete block wall with exterior insulation + beam were studied in detail in 5 steps. These steps are general behavior of components within the total measurement time of about one month, differences between wall and beam temperatures in all measurements, variation of section temperatures, variation of minimum, maximum and average temperatures measured in the environment and the surfaces, heat flow through the external surface of beam.
\end{abstract}

Keywords: Thermal bridges, Thermal insulation effect, Thermal behavior, Heat flow, Surface temperature

\footnotetext{
* Yazışmaların yapılacağı yazar: Filiz Şenkal Sezer, Uludă̆ Üniversitesi Mimarlık Fakültesi, Mimarlık Bölümü, Bursa, filizss@gmail.com
} 


\section{GİRIŞ}

Günümüzde binaların enerji verimliliğinin artırılması ve yıllık 1sıtma enerjisi ihtiyaçlarının azaltılmasında isı kayıplarının minimumda tutulması oldukça büyük önem taşımaktadır. Yüksek 1sı kayıplarının gerçekleştiği alanlar olan 1sı köprülerinde ve duvarlarda yanlış malzeme seçimi ve yanlış yalıtım uygulamaları, binaların yıllık 1sıtma enerjisi ihtiyaçlarının artmasına, 1s1 kayıplarına, yoğuşmaya, 1sıl konforun sağlanamamasına ve enerji sarfiyatının artması nedeniyle çevre kirliliğine sebep olmaktadır. Isı köprüleri ve dış duvarlar binalarda 1sı iletiminin yüksek oranda gerçekleştiği bölgelerdir. $\mathrm{Bu}$ bölgelerde gerçekleşen 1sı iletimi; 1S1 kayıpları, düşük iç yüzey sıcaklıkları, iç yüzeylerde terleme, yoğuşma, küf oluşumlarına sebep olabilmektedir.

Çalışmada sırasıyla aşağıdaki metodlar izlenmiştir:

Literatür Analizi: Konuyla ilgili ulusal ve uluslararası çalışmalar incelenmiştir.

Deneysel Çalışma: Kullanım halindeki binalar üzerinde gerçekleştirilen gerçek şartlar altındaki ölçüm değerleri esas alınmıştır.

Değerlendirme: Seçilen duvar kesitlerinin (ara kat döşemelerinin) 1sıl davranışları ölçüm sonuçlarından faydalanılarak değerlendirilmiştir.

\section{LITERATÜR ANALİİ}

Konuyla ilgili olarak incelenen ulusal ve uluslararası çalışmalar aşağıdaki Çizelge 1'de özetlenmiştir.

Çizelge 1. Literatür analizi

\begin{tabular}{|l|l|}
\hline Çalışmaların İçeriği: & Literatür Analizi: \\
\hline ISI TRANSFERİ: Isı & $\bullet$ X. Lü, 2002・E. \\
transferi konusunda & Nannei, C., Schenone, \\
nümerik ve & $1999 \cdot$ R. K. L. \\
analitik+nümerik & Sripada, D. Angirasa, \\
çözümlerin kullanıldığı & 2001・A. Al-Anzia, M. \\
yöntem arayışları & Krarti, 2004 \\
& \\
\hline
\end{tabular}

\begin{tabular}{|c|c|}
\hline $\begin{array}{l}\text { ISI İLETİMİ: Isı iletimi, } \\
\text { buhar iletimi, hava } \\
\text { hareketleri ile ilgili } \\
\text { problemlerin } \\
\text { çözülebildiği paket } \\
\text { programlarının; } \\
\text { tekrarlanabilirliğinin, } \\
\text { doğruluğunun, } \\
\text { kullanıcının müdahale } \\
\text { edebilmesinin ve } \\
\text { sağlanması. Isı } \\
\text { köprülerindeki 1sı } \\
\text { iletiminin modellenmesi. } \\
\text { Binalarda dış yüzey } \\
\text { sıcaklıklarının } \\
\text { karşılaştırılması ve } \\
\text { duvarlarda ısı iletimini } \\
\text { değiştirecek kesit } \\
\text { değişikliklerinin } \\
\text { belirlenmesi amacıyla } \\
\text { termal kamera } \\
\text { kullanılması. Isı iletimi ve } \\
\text { 1sı köprülerinde } \\
\text { gerçekleşen 1sı kayıpları } \\
\text { üzerindeki bölgesel } \\
\text { etkilerin incelenmesi }\end{array}$ & 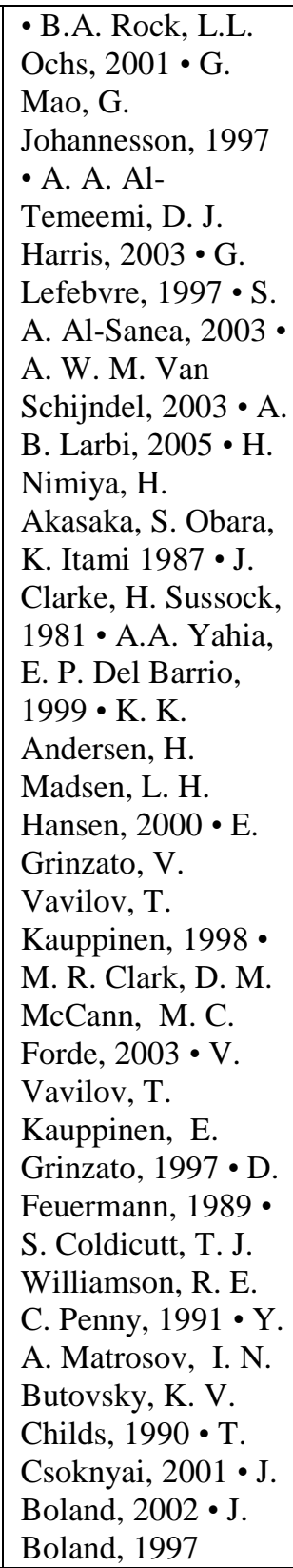 \\
\hline $\begin{array}{l}\text { FARKLI YAPI } \\
\text { ELEMANLARI: } \\
\text { Homojen duvarlar dışında } \\
\text { hafif çelik strüktürlerin, } \\
\text { çok tabakalı duvar } \\
\text { elemanlarının, } \\
\text { izolasyonlu duvar } \\
\text { panellerinin, duvar-kapı }\end{array}$ & $\begin{array}{l}- \text { S. Hassid, 1989・ } \\
\text { T. Höglund, H. } \\
\text { Burstrand, 1998・S. } \\
\text { Hassid, 1990・ Y. A. } \\
\text { Matrosov, I. N. } \\
\text { Butovsky, 1989・H. } \\
\text { Schwab, C. Stark, J. } \\
\text { Wachtel, H. P. Ebert, }\end{array}$ \\
\hline
\end{tabular}




\begin{tabular}{|c|c|}
\hline $\begin{array}{l}\text { arasında oluşan 1S1 } \\
\text { köprülerinin incelenmesi }\end{array}$ & $\begin{array}{l}\text { J. Fricke, } 2005 \cdot \mathrm{K} . \\
\text { Fukuyo, } 2003\end{array}$ \\
\hline Çalışmaların İçeriği: & Literatür Analizi: \\
\hline $\begin{array}{l}\text { PENCERELER: } \\
\text { Pencerelerde 1s1 köprüsü } \\
\text { oluşumunun en aza } \\
\text { indirilmesi }\end{array}$ & $\begin{array}{l}\text { - A. E. Ben-Nakhi, } \\
2002 \text { - C. Zürcher, } \\
1985\end{array}$ \\
\hline $\begin{array}{l}\text { DUVAR BLOKLARI: } \\
\text { Duvar örmek için } \\
\text { kullanılan blokların } \\
\text { oluşturduğu 1sı } \\
\text { köprülerinde nümerik } \\
\text { çözümlerin araştırılması }\end{array}$ & $\begin{array}{l}\text { - B. Lacarriere, B. } \\
\text { Lartigue, F. } \\
\text { Monchoux, } 2003\end{array}$ \\
\hline $\begin{array}{l}\text { ISI TRANSFERI: Isı } \\
\text { transferi konusunda } \\
\text { nümerik ve } \\
\text { analitik+nümerik } \\
\text { çözümlerin kullanıldığı } \\
\text { yöntem arayışları } \\
\end{array}$ & $\begin{array}{l}\bullet \text { X. Lü, 2002・E. } \\
\text { Nannei, C., Schenone, } \\
\text { 1999・R. K. L. } \\
\text { Sripada, D. Angirasa, } \\
\text { 2001・A. Al-Anzia, M. } \\
\text { Krarti, 2004 }\end{array}$ \\
\hline $\begin{array}{l}\text { STANDARTLAR: Is1 } \\
\text { köprüleri ile ilgili } \\
\text { büyüklüklerin } \\
\text { hesaplanmas1, Is1 } \\
\text { köprüleri ile ilgili } \\
\text { uluslararası standartlar, } \\
\text { ISO 9164'de 1s1 köprüleri } \\
\text { için verilen parametrelerin } \\
\text { belirlenmesi ve } \\
\text { kullanılması }\end{array}$ & $\begin{array}{l}\bullet \text { ISO 6946/2-1986 } \\
\text { •EN ISO 13789-1999 } \\
\text { • EN ISO 13370-1998 } \\
\text { • TS EN ISO 10211- } \\
1 \text { - 2000 • ISO 10211- } \\
2 \text { • Ş. Dilmac, A. } \\
\text { Güner, F., Ş. Sezer, S. } \\
\text { Kartal, 2007• Ş. } \\
\text { Dilmaç, Ö. Alamut, } \\
\text { 2003, • Ş. Dilmac, A. } \\
\text { Güner, A. Can, G. } \\
\text { Kaygusuzoğlu, M. T. } \\
\text { Cihan, F., Ş. Sezer, S. } \\
\text { Kartal, Ö. Kalpak } \\
\text { 2005 }\end{array}$ \\
\hline $\begin{array}{l}\text { ISI KÖPRÜLERINDE } \\
\text { FARKLI YALITIM } \\
\text { SİSTEMLERİ: Farklı } \\
\text { yalıtım sistemlerinde } \\
\text { kirişli betonarme döşeme } \\
\text { üzerindeki ısı köprülerinin } \\
\text { 1sıl davranışlarının paket } \\
\text { program kullanılarak } \\
\text { incelenmesi }\end{array}$ & $\begin{array}{l}\text { • Ş. Dilmaç, A.Can, S. } \\
\text { Kartal, 2004 • Ş. } \\
\text { Dilmaç, A. Güner, Ö. } \\
\text { Alamut, 2004 • Ş. } \\
\text { Dilmaç, M. T. Cihan, } \\
\text { A. Güner, 2004 • Ş. } \\
\text { Dilmaç, A. Can, F. Ş. } \\
\text { Sezer, 2004 • T. } \\
\text { Cihan, F. Ş. Sezer, Ş. } \\
\text { Dilmaç, 2005 • G. } \\
\text { Akgün, Ş. Dilmaç, } \\
2005\end{array}$ \\
\hline
\end{tabular}

\begin{tabular}{|l|l|}
\hline PAKET & $\bullet$ F. Deque, F. \\
PROGRAMLAR: Paket & Ollivier, J. J. Roux, \\
programlardan çıkan & 2001・J. Kosny, E. \\
sonuçların tüm binanın & Kossecka, 2002・K. \\
1sıl performansının detaylı & W. Childs, 1988 \\
bir şekilde incelendiği \\
geniş kapsamlı paket \\
programlarda \\
kullanılabilirliğinin \\
sağlanması
\end{tabular}

\section{DENEYSEL ÇALIŞMA}

$\mathrm{Bu}$ çalışmada; 1sı köprülerinin 1sıl davranış1 üzerinde 1s1 yalıtımının yeri ve duvar malzemesinin etkisi, kullanım halindeki binalar üzerinde gerçekleştirilen gerçek şartlar altındaki ölçüm değerleri esas alınarak incelenmiştir. Ortam sıcaklıkları iç ve dış tarafta aynı doğrultu üzerine gelecek şekilde hem kiriş ve hem de duvar önünde alınmıştır ( 'Campbell Scientific, Inc.' marka ve '108-L temperature sensor' model ortam sicaklık sensörü). Isı akısı kiriş üzerinde ve iç yüzeyde ölçülmüştür (Hukseflux marka ve 'HFP01 Heat Flux Plate' model 1sı akısı sensörü). Bir dakika ara ile alınan ölçümlerin 15 dakika'lık ortalamalarından oluşan veriler, data logger'da depolanmıştır (Campbell Scientific, Inc. marka ve CR200 model). Deneylere başlamadan önce deneme ölçümleri yapılmıştır.

Deneysel çalışmanın uygulandığı kesitler; yalıtımsız tuğla duvar + kiriş, yalıtımsız gazbeton duvar + kiriş, yalıtımsız hafif tuğla duvar + kiriş, çift duvar arası yalıtımlı tuğla duvar + kiriş ve dışarıdan yalıtımlı eps katkılı beton blok duvar + kiriş şeklindedir (Şekil 1).

Deneysel çalışma, aşağıdaki bölümlerde açıklanmakta olan 5 adımda gerçekleştirilmiştir:

1. Tüm ölçüm süresi (yaklaşık bir ay) içindeki genel davranışlar

2. Tüm ölçümlerde duvar ve kiriş sıcaklıkları arasındaki farklar

3. Kiriş ve duvar seviyelerindeki kesit sıcaklıklarının değişimi 
4. Kiriş ve duvar seviyelerindeki ortam ve yüzeylerde ölçülen minimum, ortalama ve maksimum sıcaklıkların değişimi

\section{Kiriş seviyesinde iletilen 1sı akısı değişimi}
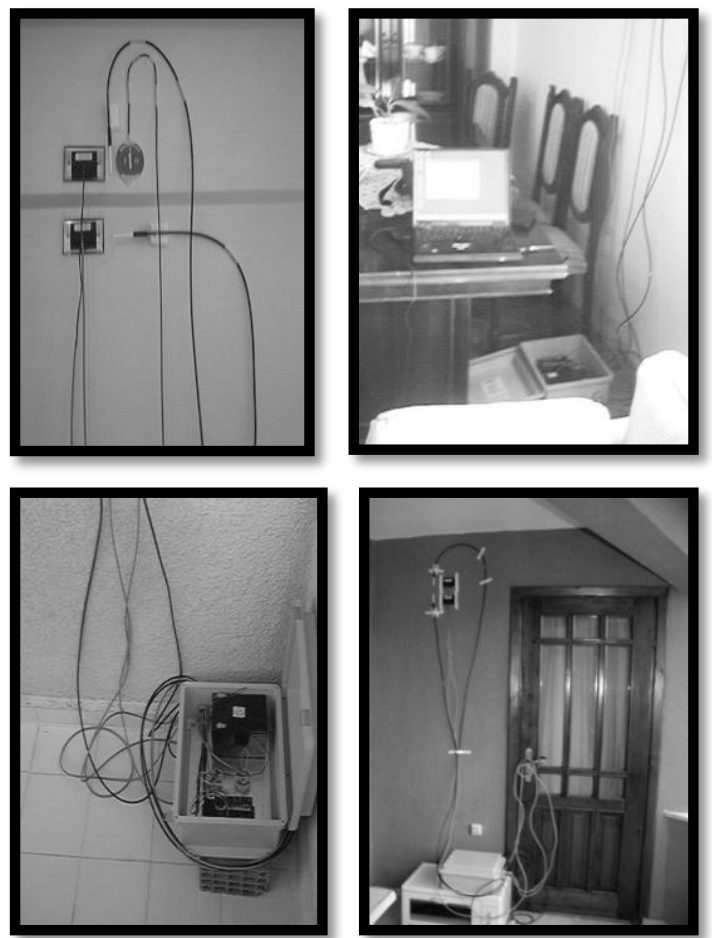

Şekil 1. Binalarda problar ve veri depolama birimlerinin yerinde görünüşü

\subsection{Tüm Ölçüm Süresi (Yaklaşık Bir Ay) İçindeki Genel Davranışlar}

İlk adımda kesitlerin ısıl davranışları tüm ölçüm süresi esas alınarak karşılaştırılmıştır. Ortaya çıkan sonuçlar hem kesit özelliği grubu arasında, hem de tüm kesitler arasında iyiden (1) kötüye (5) doğru sıralanmıştır. Son sütunda her kesitin farklı çizelge sonuçlarına göre sıralaması gösterilmiştir. En düşük numara en iyi ısıl davranış gösteren kesiti, en yüksek numara ise en kötü isıl davranış gösteren kesiti tanımlamaktadır. Çizelge ve şekillerde kullanılan kısaltmalar aşağıdaki şekildedir: $\theta_{\mathrm{i}}$ : İç ortam sıcaklığ 1

$\theta_{\text {iok}}$ : İç ortam kiriş

sicaklığ 1

$\theta_{\text {iod }}$ : İç ortam duvar

sicaklığ

$\theta_{\text {iyk: }}$ : İç yüzey kiriş

sicaklığ

$\theta_{\text {iyd }}$ : İç yüzey duvar

sicaklığg1 $\theta_{\mathrm{d}}:$ Diş ortam sicaklığ

$\theta_{\text {dok }}:$ Diş ortam kiriş

sicaklığ

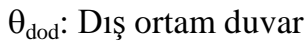

sicaklığ

$\theta_{\text {dyk }}$ : Diş yüzey kiriş

sicaklığ

$\theta_{\text {dyd }}$ : Diş yüzey duvar

sicaklığı

Ölçüm süresince kiriş önünde iç yüzey ve iç ortam sıcaklıkları arasındaki ortalama fark açısından, sıfır değeri ile dışarıdan yalıtımlı kesit en iyi; $4^{\circ} \mathrm{C}$ fark ile gazbeton duvarlı kesit en kötü kesit olmaktadır (Çizelge 2). Ölçüm süresince duvar önünde iç yüzey ve iç ortam sıcaklıkları arasındaki ortalama fark açısından ise yine en iyi kesit sıfır değeri ile dışarıdan yalıtımlı kesit olmakla beraber sıralama değişmekte ve en kötü kesit $3^{\circ} \mathrm{C}$ ile çift duvar arası yalıtımlı kesit olmaktadır (Şekil 2).

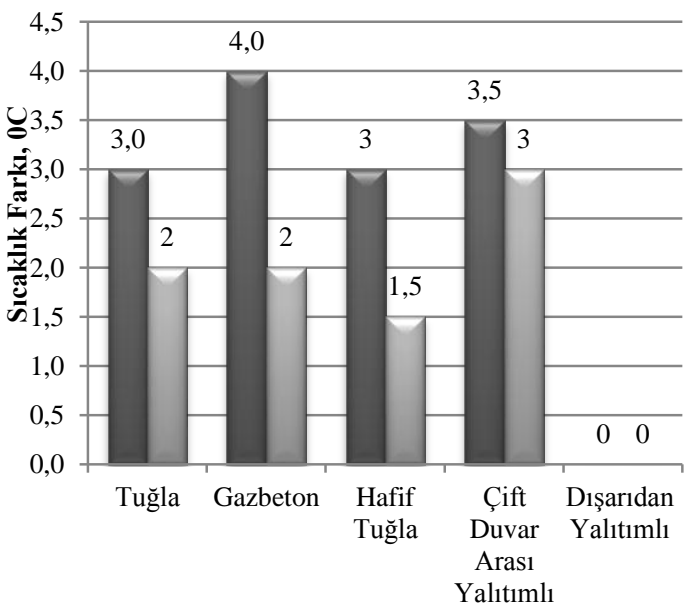

Kesit Özelliği

घkiriş önünde ortalama sıcaklık farkı

घduvar önünde ortalama sıcaklık farkı

Şekil 2. İç yüzey sıcaklığı $\left(\theta_{\text {iy }}\right)$ ile iç ortam sıcaklığı $\left(\theta_{\mathrm{i}}\right)$ arasındaki farkın değişimi 
Çizelge 2. Kesitlerde iç yüzey sıcaklığı ( $\theta$ iy) ile iç ortam sıcaklığg $\left(\theta_{\mathrm{i}}\right)$ arasındaki farkın değişimi

\begin{tabular}{|c|c|c|c|c|c|}
\hline \multirow{2}{*}{\multicolumn{2}{|c|}{ Kesit özelliği }} & \multirow{3}{*}{$\begin{array}{l}\text { Ölçüm süresince kiriş } \\
\text { önünde iç yüzey ve iç } \\
\text { ortam } \begin{array}{r}\text { sicaklıkları } \\
\text { arasındaki } \\
\text { fark, }{ }^{\circ} \mathrm{C}\end{array} \\
\end{array}$} & \multirow{3}{*}{$\begin{array}{l}\text { Ölçüm süresince } \frac{\text { duvar }}{\text { önünde iç yüzey ve iç }} \\
\text { ortam sicaklıkları } \\
\text { arasındaki ortalama fark, } \\
{ }^{\circ} \mathrm{C} \\
2\end{array}$} & \multicolumn{2}{|c|}{ Değerlendirme sıralaması } \\
\hline & & & & \multirow{2}{*}{$\begin{array}{c}\text { Grup içinde } \\
\text { (2) }\end{array}$} & \multirow{2}{*}{$\begin{array}{c}\text { Tüm kesitler içinde } \\
\text { (3) }\end{array}$} \\
\hline \multirow{3}{*}{ 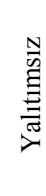 } & Tuğla & & & & \\
\hline & Gazbeton & 4 & 2 & (3) & (4) \\
\hline & Hafif Tuğla & 3 & 1,5 & (1) & (2) \\
\hline \multirow{2}{*}{ 青 } & $\begin{array}{c}\text { Çift Duvar } \\
\text { Arası } \\
\text { Yalıtımlı }\end{array}$ & 3,5 & 3 & (2) & (5) \\
\hline & $\begin{array}{c}\text { Dişarıdan } \\
\text { Yalıtımlı }\end{array}$ & 0 & 0 & (1) & (1) \\
\hline
\end{tabular}

\subsection{Tüm Ölçümlerde Duvar ve Kiriş Sıcaklıkları Arasındaki Farklar}

İkinci adımda kesitler, duvar ve kiriş sıcaklıkları arasındaki fark açısından karşılaştırılmıştır. Kesitlerin karşılaştırmasını yaparken kolaylık sağlaması için şekilleri oluşturan noktalardan doğru geçirilmiş ve Çizelge 3'deki değerlendirmeler bu doğrular üzerinden yapılmıştır.

Is1 iletkenlik değeri yüksek olduğu için tüm kesitlerde (5. sütun) betonarme kirişlerde yüzey sıcaklıkları (dışarıdan yalıtımlı kesit hariç) duvar yüzey sıcaklıklarından yüksek çıkmaktadır. Dışarıdan yalıtımlı kesitte kirişlerin de yalıtılıyor olması, bu değerin iç yüzeyde duvarla eşit olmasını sağlamaktadır (Şekil 3).

\subsection{Kiriş ve Duvar Seviyelerindeki Kesit Sıcaklıklarının Değişimi}

Üçüncü adımda kesitler, kiriş seviyesindeki ve duvar seviyesindeki kesit sıcaklıklarının değişimi açısından karşılaştırılmıştır. (Dışarıdan yalıtımlı kesit haricinde) kiriş seviyesinde ortamla yüzey sıcaklıkları arasındaki fark, iç ortamda dış

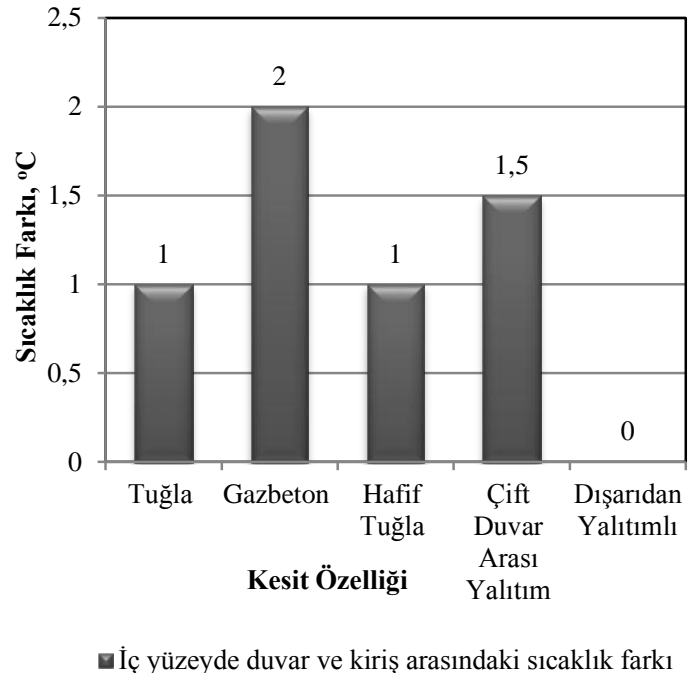

Şekil 3. Ölçüm alınan kesitlerde duvar $\left(\theta_{\mathrm{d}}\right)$ ve kiriş sıcaklıklarının $\left(\theta_{\mathrm{k}}\right)$ karşılaștırması

ortamdakinden daha büyüktür $\left(\theta_{\text {iok }}-\theta_{\text {iyk }}\right)>$ $\left(\theta_{\mathrm{dyk}}-\theta_{\mathrm{dok}}\right)$ (Çizelge 4$)$.

Duvar seviyesinde de benzer durum söz konusudur; $\left(\theta_{\text {iod }}-\theta_{\text {iyd }}\right)>\left(\theta_{\text {dyd }}-\theta_{\text {dod }}\right)$ ancak farklar iç 
Çizelge 3. Ölçüm alınan kesitlerde duvar $\left(\theta_{\mathrm{d}}\right)$ ve kiriş sıcaklıklarının $\left(\theta_{\mathrm{k}}\right)$ karşılaştırması

\begin{tabular}{|c|c|c|c|c|c|c|c|}
\hline \multirow{2}{*}{\multicolumn{2}{|c|}{ Kesit Özelliği }} & \multirow{3}{*}{$\begin{array}{l}\text { Diş Ortam } \\
\begin{array}{c}\text { Duvar } \\
\text { Kiriş }\end{array}\end{array}$} & \multirow{3}{*}{$\begin{array}{c}\text { İç Ortam } \\
\text { Duvar } \cong \text { Kiriş }\end{array}$} & \multirow{3}{*}{$\begin{array}{c}\text { Dış Yüzey } \\
\text { Duvar < Kiriş̧ } \\
\left(\cong 1^{\circ} \mathrm{C}\right)\end{array}$} & \multirow{2}{*}{ İç Yüzey } & \multicolumn{2}{|c|}{$\begin{array}{c}\text { Değerlendirme } \\
\text { Sıralamas1 }\end{array}$} \\
\hline & & & & & & Grubu icinde & Tüm kesitler \\
\hline \multirow{3}{*}{ 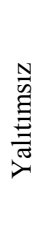 } & Tuğla & & & & $\begin{array}{c}\text { Duvar }>\text { Kiriş } \\
\left.1^{\circ} \mathrm{C}\right)\end{array}$ & (1) & (2) \\
\hline & Gazbeton & $\begin{array}{c}\text { Duvar } \cong \\
\text { Kiriş }\end{array}$ & Duvar > Kiriş & $\begin{array}{c}\text { Duvar }<\text { Kiriş̧ } \\
\quad\left(\cong 1^{\circ} \mathrm{C}\right)\end{array}$ & $\begin{array}{c}\text { Duvar }>\text { Kiriş̧ } \\
\left.2^{\circ} \mathrm{C}\right)\end{array}$ & (1) & (2) \\
\hline & Hafif Tuğla & $\begin{array}{c}\text { Duvar }< \\
\text { Kiriş }\end{array}$ & Duvar < Kiriş & $\begin{array}{c}\text { Duvar < Kiriş } \\
\quad\left(\cong 1^{\circ} \mathrm{C}\right)\end{array}$ & $\begin{array}{c}\text { Duvar > Kiriş̧ } \\
\left.1{ }^{\circ} \mathrm{C}\right)\end{array}$ & (1) & (2) \\
\hline \multirow{2}{*}{  } & $\begin{array}{c}\text { Çift Duvar ars. } \\
\text { Yaltım }\end{array}$ & $\begin{array}{c}\text { Duvar }< \\
\text { Kiriş }\end{array}$ & $\begin{array}{c}\text { Duvar }>\text { Kiriş } \\
\left.\cong 1^{\circ} \mathrm{C}\right)\end{array}$ & $\begin{array}{l}\text { Duvar }<\text { Kiriş } \\
\quad\left(\cong 1,5^{\circ} \mathrm{C}\right)\end{array}$ & $\begin{array}{cc}\text { Duvar } & >\text { Kiriş } \\
& \left.1,5^{\circ} \mathrm{C}\right)\end{array}$ & (2) & (2) \\
\hline & $\begin{array}{r}\text { Dişarıdan } \\
\text { Yalıtımlı }\end{array}$ & $\begin{array}{c}\text { Duvar > } \\
\text { Kiriş }\end{array}$ & Duvar = Kiriş & Duvar $<$ Kiriş̧ & Duvar $=$ Kiriş & (1) & (1) \\
\hline
\end{tabular}

Çizelge 4. Duvar ve kirişlerde ortam ve yüzey sıcaklık farklarının karşılaştırması

\begin{tabular}{|c|c|c|c|c|c|c|c|c|c|}
\hline \multirow{2}{*}{\multicolumn{2}{|c|}{ Kesit Özelliği }} & \multicolumn{3}{|c|}{$\operatorname{Kiriş}\left({ }^{\circ} \mathrm{C}\right)$} & \multicolumn{3}{|c|}{ Duvar $\left({ }^{\circ} \mathrm{C}\right)$} & \multicolumn{2}{|c|}{ Değerlendirme Sıralaması } \\
\hline & & $\theta_{\text {iok }}-\theta_{\text {iyk }}$ & $\theta_{\mathrm{iyk}}-\theta_{\mathrm{dyk}}$ & $\theta_{\text {dyk }}-\theta_{\text {dok }}$ & $\theta_{\text {iod }}-\theta_{\text {iyd }}$ & $\theta_{\text {iyd }}-\theta_{\text {dyd }}$ & $\theta_{\mathrm{dyd}}-\theta_{\text {od }}$ & $\begin{array}{l}\text { Grubu } \\
\text { icinde }\end{array}$ & Tüm kesit içinde \\
\hline \multirow{3}{*}{ 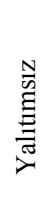 } & Tuğla & 3 & 9 & 2 & 2 & 11 & 1 & (1) & (2) \\
\hline & $\begin{array}{c}\mathrm{Gaz} \\
\text { Beton }\end{array}$ & 4 & 10 & 2 & 2 & 13 & 1,5 & (1) & (2) \\
\hline & Hafif Tuğla & 3 & 6 & 2 & 1,5 & 8 & 1,5 & (1) & (2) \\
\hline \multirow{2}{*}{ 音 } & $\begin{array}{c}\text { Cift Duvar } \\
\text { Arası Yalıtım }\end{array}$ & 3,5 & 9 & 3 & 3 & 12 & 1,5 & (2) & (2) \\
\hline & $\begin{array}{c}\text { Dışarıdan } \\
\text { Yalıtım }\end{array}$ & 0 & 4,5 & 2 & 0 & 4,5 & 1 & (1) & (1) \\
\hline
\end{tabular}

ve dış ortamda birbirine daha yaklaşmıştır. Dışarıdan yalıtımlı kesitte iç ortamda ortamla yüzey sıcaklıkları arasındaki fark dışarıdan sürekli yalıtımın olumlu etkisi sonucu $\left(\theta_{\text {iok }}-\theta_{\text {iyk }}\right)$ sıfırdır. İç ve dış yüzey arasındaki sıcaklık farkları - dışarıdan yalıtımlı kesitte kiriş ve duvar seviyesinde de aynıdır. $\left(4,5^{\circ} \mathrm{C}\right)$ Diğerlerinde kirişlerin yalıtılmamış olması dolayısıyla duvar seviyesinde kiriş seviyesinden daha büyüktür ( (Şekil 4).
Çizelge 5'de, duvarın yüzey sıcaklıkları arasındaki farkın kiriş yüzey sıcaklıkları arasındaki farktan olan büyüklüğü (Өiyd- $\theta$ dyd)-( $\theta$ iyk- $\theta$ dyk) karşılaştırılmıştır. Bu fark en fazla gazbeton kesitte görülmektedir. Duvar yüzey sıcaklıkları ve kiriş yüzey sıcaklıkları arasındaki fark açısından yine dışarıdan yalıtımlı kesit en iyi, gazbeton duvarlı kesit ise en kötü olmaktadır. Fark büyüdükçe kesit isıl konfor açısından daha olumsuz olmaktadır (Şekil 5). 
Çizelge 5. Ortamlar arasındaki duvar ve kiriş yüzey sıcaklıkları arasındaki farkın karşılaştırılması

\begin{tabular}{|c|c|c|c|c|c|c|c|c|}
\hline & \multirow{2}{*}{ esit özelliği } & \multirow{2}{*}{ 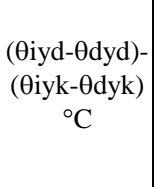 } & \multirow{2}{*}{$\begin{array}{l}\theta \text { io } \\
{ }^{\circ} \mathrm{C}\end{array}$} & \multirow{2}{*}{$\begin{array}{c}\theta \text { do } \\
{ }^{\circ} \mathrm{C}\end{array}$} & \multirow{2}{*}{$\begin{array}{l}\theta \text { io- } \theta \text { do } \\
{ }^{\circ} \mathrm{C}\end{array}$} & \multirow{2}{*}{$\begin{array}{c}\text { Duvar sıcaklıkları ile kiriş } \\
\text { sıcaklıkları arasındaki } \\
\text { farkın, ortam sıcaklıkları } \\
\text { arasındaki farka oranı }\end{array}$} & \multicolumn{2}{|c|}{ Değerlendirme Siralaması } \\
\hline & & & & & & & $\begin{array}{l}\text { Grubu } \\
\text { içinde }\end{array}$ & Tüm kesitler içinde \\
\hline \multirow{3}{*}{ 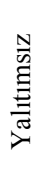 } & Tuğla & 2 & 24 & 11 & 13 & 0,15 & (1) & (2) \\
\hline & Gaz beton & 4 & 23,5 & 6,5 & 17 & 0,24 & (3) & (4) \\
\hline & Hafif Tuğla & 2 & 20,5 & 10 & 10,5 & 0,19 & (2) & (3) \\
\hline \multirow{2}{*}{ 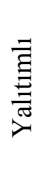 } & $\begin{array}{l}\text { Çift Duvar } \\
\text { Aras1 Yalıtım }\end{array}$ & 3 & 21,5 & 5,5 & 16 & 0,19 & (2) & (3) \\
\hline & $\begin{array}{l}\text { Dişarı dan } \\
\text { Yalıtım }\end{array}$ & 0 & 18 & 13 & 5 & 0 & (1) & (1) \\
\hline
\end{tabular}

Çizelge 6. Kesitlerde duvar ve kiriş seviyelerinde ölçülen ortalama, minimum ve maksimum sıcaklıkların farklarının karşılaştırması

\begin{tabular}{|c|c|c|c|c|c|c|c|}
\hline & \multirow{2}{*}{\multicolumn{2}{|c|}{ Kesit özelliği }} & \multirow{3}{*}{$\begin{array}{c}\begin{array}{c}\text { Ort. } \\
\text { Sicaklik }^{\circ} \mathrm{C}\end{array} \\
13,8\end{array}$} & \multirow{3}{*}{$\begin{array}{c}\text { Min. Sicaklık }{ }^{\circ} \mathrm{C} \\
21,0\end{array}$} & \multirow{3}{*}{$\begin{array}{c}\begin{array}{c}\text { Max. } \\
\text { Sicaklik }^{\circ} \mathrm{C}\end{array} \\
1,9 \\
\end{array}$} & \multicolumn{2}{|c|}{ Değerlendirme Sıralaması } \\
\hline & & & & & & Grubu & Tüm kesitler \\
\hline \multirow{12}{*}{ 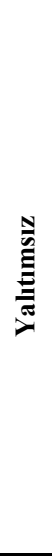 } & \multirow{4}{*}{$\stackrel{\frac{\pi}{100}}{\Xi}$} & $\Delta \theta_{\text {duvar ortam }}$ & & & & \multirow{4}{*}{ (1) } & \multirow{4}{*}{ (2) } \\
\hline & & $\Delta \theta_{\text {kiriş ortam }}$ & 13,8 & 20,7 & 2,4 & & \\
\hline & & $\Delta \theta_{\text {duvar yüzey }}$ & 10,7 & 18,0 & 0,2 & & \\
\hline & & $\Delta \theta_{\text {kiriş yüzey }}$ & 8,9 & 15,1 & 0,5 & & \\
\hline & \multirow{4}{*}{ 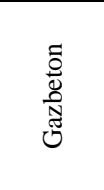 } & $\Delta \theta_{\text {duvar ortam }}$ & 17,1 & 21,7 & 6,5 & \multirow{4}{*}{ (3) } & \multirow{4}{*}{ (4) } \\
\hline & & $\Delta \theta_{\text {kiriş ortam }}$ & 16,9 & 21,7 & 8,5 & & \\
\hline & & $\Delta \theta_{\text {duvar yüzey }}$ & 13,2 & 21,4 & 1,1 & & \\
\hline & & $\Delta \theta_{\text {kiris yüzey }}$ & 10,2 & 16,9 & 1,9 & & \\
\hline & \multirow{4}{*}{  } & $\Delta \theta_{\text {duvar ortam }}$ & 10,0 & 14,5 & 2,9 & \multirow{4}{*}{ (2) } & \multirow{4}{*}{ (3) } \\
\hline & & $\Delta \theta_{\text {kiriş ortam }}$ & 10,4 & 13,8 & 3,7 & & \\
\hline & & $\Delta \theta_{\text {duvar yüzey }}$ & 8,0 & 11,6 & 2,2 & & \\
\hline & & $\Delta \theta_{\text {kiris yüzey }}$ & 6,0 & 8,2 & 1,9 & & \\
\hline \multirow{8}{*}{ 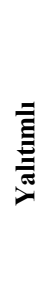 } & \multirow{4}{*}{ 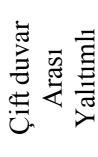 } & $\Delta \theta_{\text {duvar ortam }}$ & 16,7 & 22,2 & 10,9 & \multirow{4}{*}{ (2) } & \multirow{4}{*}{ (5) } \\
\hline & & $\Delta \theta_{\text {kiriș ortam }}$ & 15,5 & 21,5 & 21,5 & & \\
\hline & & $\Delta \theta_{\text {duvar yüzey }}$ & 12,0 & 8,9 & 8,9 & & \\
\hline & & $\Delta \theta_{\text {kiris yüzey }}$ & 8,8 & 15,7 & 6,5 & & \\
\hline & \multirow{4}{*}{ 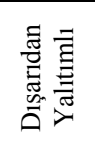 } & $\Delta \theta_{\text {duvar ortam }}$ & 4,4 & 16,0 & $-13,0$ & \multirow{4}{*}{ (1) } & \multirow{4}{*}{ (1) } \\
\hline & & $\Delta \theta_{\text {kiriş ortam }}$ & 4,7 & 16,1 & $-10,4$ & & \\
\hline & & $\Delta \theta_{\text {duvar yüzey }}$ & 2,9 & 16,4 & $-28,2$ & & \\
\hline & & $\Delta \theta_{\text {kiris yüzey }}$ & 2,5 & 16,2 & $-24,9$ & & \\
\hline
\end{tabular}




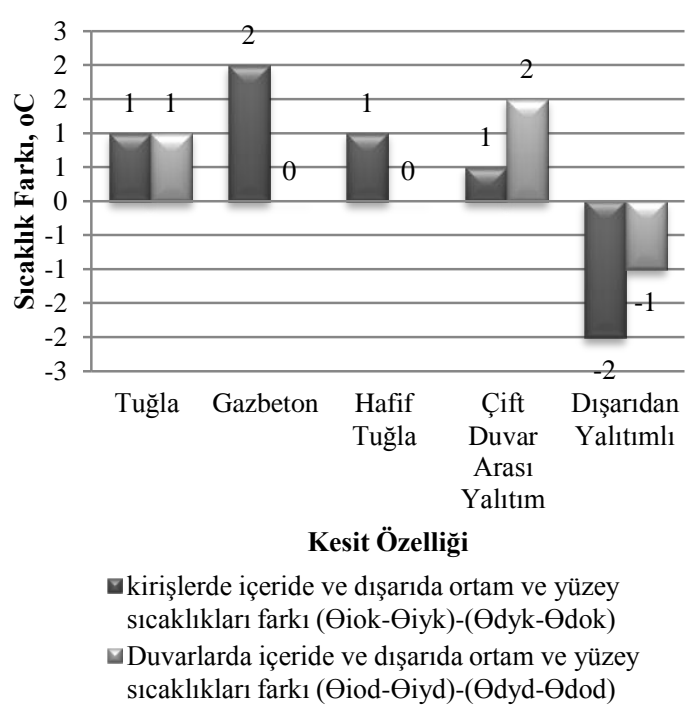

Şekil 4. Duvar ve kirişlerde ortam ve yüzey sıcaklık farklarının karşılaş̧ırması

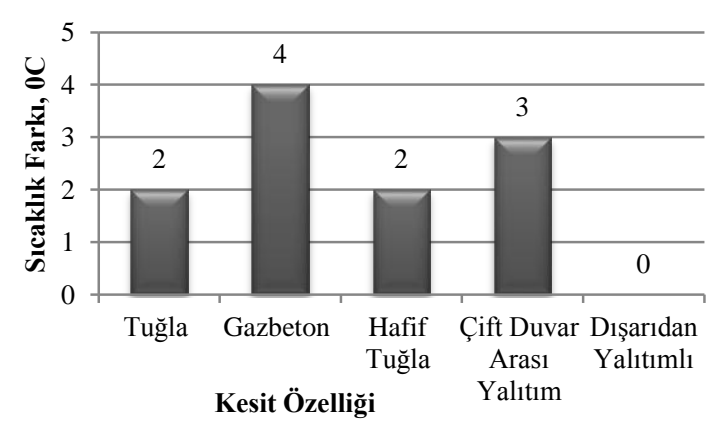

घiç ortamda duvar ve kiriş yüzey sıcaklıkları arasındaki fark

Şekil 5. Ortamlar arasındaki duvar ve kiriş yüzey sıcaklıkları arasındaki farkın karşılaştırılması

\subsection{Kiriş ve Duvar Seviyelerindeki Ortam ve Yüzeylerde Ölçülen Minimum, Ortalama ve Maksimum Sıcaklıkların Değişimi}

Dördüncü adımda kesitler, kiriş ve duvar seviyelerinde ölçülen minimum, ortalama ve maksimum sıcaklıkların değişimi açısından karşılaştırılmıştır. Ortamlar arası sıcaklık farkı üzerinde ölçüm seviyesinin yerinin (kiriş veya duvar önünde olması) fazla etkili olmadığı görülmüştür. Her iki durum için de sıcaklık farkı ( $\Delta \theta_{\text {duvar ortam }}$ ve $\Delta \theta_{\text {kiriş ortam }}$ ) hemen hemen aynı çıkmaktadır (Çizelge 6).

Sadece çift duvar arası yalıtımlı kesitte duvar seviyesinde ortamlar arasındaki sıcaklık farkı, kiriş seviyesindeki ortamlar arası sicaklık farkından $1,2^{\circ} \mathrm{C}$ daha büyük olmaktadır.

Ancak yüzeyler sıcaklık farkları beklendiği şekilde kiriş ve duvar üzerinde ölçülmesine göre $\left(\Delta \theta_{\text {duvar }}\right.$ yüzey ve $\Delta \theta_{\text {kiriş yüzey }}$ ) anlamlı fark göstermektedir. Duvar ve kiriş yüzeyleri arasındaki sıcaklık farkının artması kesit içinde farklı ısıl davranışların meydana geldiğini göstermektedir ve istenmeyen durumdur. En olumsuz durum çift duvar arası yalıtımlı kesitte görülmektedir. Duvarın yalıtımlı olmasına karşın kirişte yalıtımın kesilmesi farkın büyümesine sebep olmuştur. En iyi durum dışarıdan yalıtımlı kesitte görülmektedir. Kiriş ve duvar arasındaki fark küçüktür.

\subsection{Kiriş Seviyesinde İletilen Isı Akısı Değişimi}

Beşinci adımda kesitler, kiriş seviyesinde iletilen 1sı akısının değişimi (birim alandan birim zamanda iletilen) 1S1 enerjisi açısından karşılaştırılmıştır. Kiriş kalınlıkları birbirine yakın olmasına rağmen birim alandan birim zamanda iletilen is1 enerjisi üzerinde dışarıdan yalıtımın etkisi açıkça görülmektedir (Şekil 6).

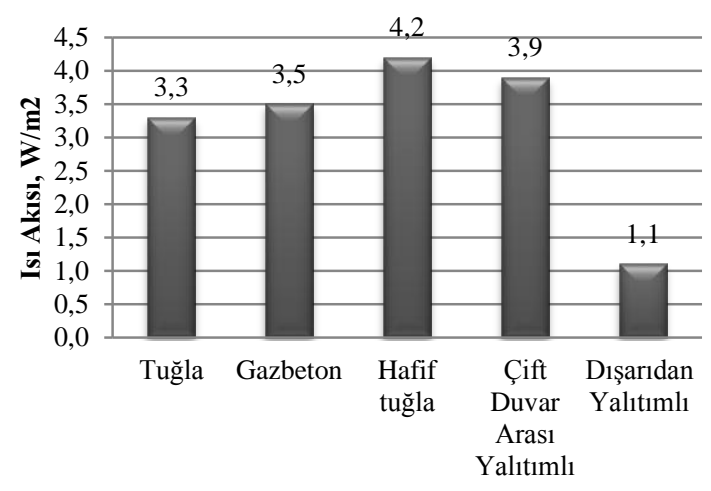

Kesit Özelliği

Şekil 6. Kesitlerde kiriş seviyesindeki 1sı akısının değişimi 
Ölçüm alınan kesitlerde kiriş seviyesinde yüzeyler arası sıcaklık farkı başına ortalama 1S1 akısı açısından yine dışarıdan yalıtımlı kesit en iyi, hafif tuğla duvarlı kesit ise en olumsuz kesit olmuştur (Çizelge 7).

\section{DEĞERLENDIRME VE SONUÇ}

$\mathrm{Bu}$ çalışmada farklı duvar malzemesi ve farklı yalıtım durumlarının binanın isıl performansına olan etkisi tespit edilmiştir. Isı iletkenlik katsayısı değerleri birbirlerinden farklı olmasına rağmen, yalıtımsız olmaları durumunda, tuğla, gazbeton ve hafif tuğla malzemelerin 1sıl davranışları birbirine yakın sonuçlar vermektedir. Değerlendirme ölçütleri arasında bir özellik için yetersiz olabilen kesit başka bir ölçüt için daha iyi sonuç verebilmektedir. Çift duvar arası yalıtımlı (kiriş yalıtımsız) kesit, duvarlar betonarme iskelet elemanların (kolon-kiriş-döşeme) arasına yerleştirildiği ve betonarme elemanlar yalıtımsız bırakıldığı için; incelenen özelliklerin çoğunda 1sı1 performans açısından en olumsuz kesiti göstermektedir. Duvarların yalıtılmış olması ve duvarın U değerinin yalıtımsız kesitlerden çok daha küçük olmasının getirdiği avantaj, yalıtımın kesilmesi sebebi ile kaybolmakta ve yalıtımsız kesitlerden daha olumsuz 1sıl davranış göstermektedir. Dışarıdan yalıtımlı kesit ise, duvar ve betonarme elemanlar kesintisiz bir yalitım ile kaplandığı için, her şartta en iyi 1 sıl davranışı göstermekte ve en olumlu kesit olmaktadır (Çizelge 8).

Çalışmanın deneysel verilere dayanıyor olması binalarda enerji verimliliğine katk1 sağlayan 1s1 yalıtım uygulamaları için güvenilir bir kaynak niteliğindedir. $\mathrm{Bu}$ çalışmadan elde edilen veriler sonucunda uygun malzeme seçimi ve doğru bir yalıtım uygulaması ile binalarda; enerji tüketiminin azaltılması, 1sı kayıplarının ve yıllık 1sıtma enerjisi ihtiyacının azaltılması, 1sıl konfor şartlarının iyileştirilmesi, enerji verimliliğinin arttırılmasi (Binalarda Enerji Performans Yönetmeliği - Enerji Kimlik Belgesi) ve çevrenin korunmasına katkı sağlanacaktır.
Konuyla ilgili ülkemizde yürürlüğe konan çeşitli yasa ve yönetmelikler bulunmaktadır. Ancak yasa ve yönetmeliklerin yerine getirilmesi/uygulanması enerjinin verimli kullanımı konusunda sadece destekleyici olacaktır. Ayrıca mimarlık eğitimi sürecinde ve sonrasında da binaların tasarımında ve ısıl konfor koşullarının sağlanmasında doğru malzeme seçimi ve doğru yalıtım sisteminin ortaya konması açısından önemli olacaktır.

$\mathrm{Bu}$ sayede farklı duvar malzemesi ve farklı yalıtım durumlarının binanın 1sıl performansına olan etkisi, binalarda gerçek şartların gerektirdiği düzeyde ve 1sı kayıplarını minimumda tutacak dış duvar uygulamalarının tespit edilmesi, optimum enerji performansını sağlayacak duvar malzemesi ve yalıtım uygulaması seçimi için veri sağlama imkanı sağlanacaktır.

Buna ek olarak mimarların tasarım aşamasında enerji verimliliğine uygun malzeme seçmesi ve tasarımlarını gerçekleştirirken fiziksel çevre parametreleri ve malzeme ilişkisini dikkate almaları daha başarılı sonuçlar doğuracaktır. Günümüz yaşam koşulları göz önüne alındığında, binaların tasarım aşamasından itibaren "ekoloji” ve "sürdürülebilirlik" kavramlarının ön planda tutulması gerekliliği bilinen bir gerçektir. Dünyada bu konuda artan bilinç ve dünya kaynaklarının hızla tükenmesi 1sı kayıplarının minimuma indirgenmesi konusunda motive edici olacaktır. Hızlı kentleşme, enerji kaynaklarının giderek azalması ve enerji konusunda dışa bağımlı bir ülke olmamız dolayısıyla, binalardaki 1s1 kayıplarını minimuma indirmek zorunlu hale gelmektedir.

\section{KAYNAKLAR}

1. Akgün, G., Dilmaç, Ş., 2005. Isı Köprüsü Problemlerinde Kullanılan Matematik Modellerin Karşılaştırılması, İTÜ Dergisi /DMühendislik Serisi, Cilt:4, Sayı:5, 3-16.

2. Al-Anzia, A., Krarti, M., 2004. Local/Global Analysis of Transient Heat Transfer from Building Foundations, Building and Environment, 39, 495-504.

3. Al-Sanea, S. A., 2003. Finite-Volume Thermal Analysis of Building Roofs Under Two- 
Çizelge 7. Kesitlerde kiriş seviyesindeki 1sı akısının değişimi

\begin{tabular}{|c|c|c|c|c|c|c|}
\hline & \multirow{2}{*}{ Kesit özelliği } & \multirow{2}{*}{$\begin{array}{l}\text { Ortalama 1s1 } \\
\text { ak1s1, W/m }\end{array}$} & \multirow{2}{*}{$\begin{array}{l}\text { Yüzeyler arası } \\
\text { ortalama sıcaklık } \\
\text { farkı, }{ }^{\circ} \mathrm{C}\end{array}$} & \multirow{2}{*}{$\begin{array}{c}\text { Yüzeyler arası sicaklık } \\
\text { farkı başıa ortalama 1S1 } \\
\text { akısı, } \mathrm{W} / \mathrm{m}^{2}\end{array}$} & \multicolumn{2}{|c|}{ Değerlendirme sıralaması } \\
\hline & & & & & $\begin{array}{l}\text { Grubu } \\
\text { içinde }\end{array}$ & $\begin{array}{l}\text { Tüm kesitler } \\
\text { içinde }\end{array}$ \\
\hline \multirow{3}{*}{ 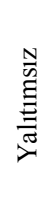 } & Tuğgla & 30 & 9,0 & 3,3 & (1) & (2) \\
\hline & Gazbeton & 35 & 10,0 & 3,5 & (2) & (3) \\
\hline & Hafif tuğla & 25 & 6,0 & 4,2 & (3) & (5) \\
\hline \multirow{2}{*}{ 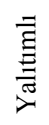 } & Çift duvar arası yalıtım & 35 & 9,0 & 3,9 & (2) & (4) \\
\hline & Dışarıdan yalıtımlı & 5 & 4,5 & 1,1 & (1) & (1) \\
\hline
\end{tabular}

Çizelge 8. Kesitlerin elde edilen sonuçlara göre değerlendirme sıralaması




Dimensional Periodic Conditions, Building and Environment, 38, 1039-1049.

4. Al-Temeemi, A. A., Harris, D. J., 2003. The Effect of Earth-Contact on Heat Transfer Through a Wall in Kuwait, Energy and Buildings, 35, 399-404.

5. Andersen, K. K., Madsen, H., Hansen, L. H., 2000. Modelling the Heat Dynamics of a Building Using Stochastic Differential Equations, Energy and Buildings, 31, 13-24.

6. Anon ISO 10211-2: Thermal Bridges in Building Construction-Heat Flows and Surface Temperatures- Part 2: Linear Thermal Bridges, the International Organization for Standardization, Geneva.

7. Ben-Nakhi, A. E., 2002. Minimizing Thermal Bridging Through Window Systems in Buildings of Hot Regions Applied Thermal Engineering, 22, 989-998.

8. Childs, K. W., 1988. Analysis of Seven Thermal Bridges İdentified in a Commercial Building, American Society of Heating, Refrigerating and Air-Conditioning Engineers (ASHRAE). Annual Meeting, Ottawa, INCONNU, 94, 1776-1792.

9. Cihan, T., Şenkal Sezer, F., Dilmaç, Ş., 2005. Ülkemizdeki Çift Duvar Arası Yalıtım Uygulamalarında Betonarme Kirişlerin Oluşturduğu Isı Köprülerinin Değerlendirilmesi, Uludağ Üniversitesi Mühendislik-Mimarlık Fakültesi Dergisi, Cilt:10, 33-47.

10. Clarke, J., Sussock, H., 1981. "Computer Graphics for Building Energy Analysis Alan Bridges", Advances in Engineering Software 3(2), 84-88.

11. Deque, F,. Ollivier, F., Roux, J. J., 2001. Effect of 2D Modelling of Thermal Bridges on the Energy Performance of Buildings Numerical Application on the Matisse Apartment", Energy and Buildings, 33(6), 583587.

12. Dilmac, S., Guner, A., Senkal Sezer, F., Kartal, S., 2007. Simple Method for Calculation of Heat Loss Through Floor/Beam-Wall Intersections According to ISO 9164. Energy Conversion and Management, 48(3), 826-835, ISSN: 0196-8904, Pergamon-Elsevier Science Ltd, Oxford, England.
13. Dilmac, Ş., Güner, A., Can, A., Kaygusuzoğlu, G., Cihan, M. T., Şenkal Sezer, F., Kartal, S., Kalpak, Ö., 2005. Döşemelerde Yanal Is1 kayıplarının Hesaplanması İçin Parametrelerin Belirlenmesi, Türkiye Bilimsel ve Teknik Araştırma Kurumu, İnşaat ve Çevre Teknolojileri Araştırma Grubu, Construction and Environmental Technologies Research Grant Committee, Proje No: İÇTAG - 1242, TÜBİTAK, sf: 1-79.

14. Dilmaç, Ş., Alamut, Ö., 2003. Comparison of International Thermal Analysis Methods of Thermal Bridges, Proceedings of the First International Energy, Energy and Environment Symposium, İzmir, 781-786.

15. Dilmaç, Ş., Can, A., Kartal, S., 2004. Ara Kat Döşemelerinin Isıl Davranışı Üzerine İklim Şartlarının ve Yalıtım Sistemlerinin Etkisi, Tesisat Mühendisliği Dergisi, Say1:82, 49-64.

16. Dilmaç, Ş., Can, A., Şenkal Sezer, F., 2004. Ara Kat Kirişli Döşemelerinde İçerden ve Dışarıdan Yalıtım Uygulamalarının Enerji Verimliliklerinin Karşılaştırılması, Tesisat Mühendisliği Dergisi, say1:80, 7-20.

17. Dilmaç, Ş., Cihan, M. T., Güner, A., 2004. Teras Çatıların Enerji Verimliliklerinin Karşılaştırılması, Dizayn Konstrüksiyon Dergisi, Say1:226, 68-77.

18. Dilmaç, Ş., Güner, A., Alamut, Ö., 2004. Teras Kat Döşemelerinin Isıl Davranışı Üzerine İklim Şartlarının Etkisi, Dizayn Konstrüksiyon Dergisi, Sayı:225, 68-83.

19. Fukuyo, K., 2003. Heat Flow Visualization for Thermal Bridge Problems, International Journal of Refrigeration, 26, 614-617.

20. Hassid, S., 1990. Thermal Bridges Across Multilayer Walls: An Integral Approach, Building and Environment, 25(2), 143-150.

21. Hassid, S., 1989. Thermal Bridges in Homogeneous Walls: A Simplified Approach, Building and Environment, , 24(3), 259-264.

22. Höglund, T., Burstrand, H., 1998. Slotted Steel Studs to Reduce Thermal Bridges in Insulated Walls, Thin-Walled Structures, 32, 81-109.

23. Kosny, J., Kossecka, E., 2002. MultiDimensional Heat Transfer through Complex Building Envelope Assemblies in Hourly Energy Simulation Programs, Energy and Buildings, 34(5), 445-454. 
24. Lacarriere, B., Lartigue, B., Monchoux, F., 2003. Numerical Study of Heat Transfer in a Wall of Vertically Perforated Bricks: Influence of Assembly Method, Energy and Buildings, 35(3), 229-237.

25. Larbi, A. B., 2005. Statistical Modelling of Heat Transfer for Thermal Bridges of Buildings, Energy and Buildings, 37, 945-951.

26. Lefebvre, G., 1997. Modal-Based Simulation of the Thermal Behaviour of a Building: the M2m Software, Energy and Buildings, 25, 1930.

27. Lü, X., 2002 .Modelling of Heat and Moisture Transfer in Buildings I. Model Program Energy and Buildings, 34 1033-1043.

28. Mao, G., Johannesson, G., 1997. Dynamic Calculation of Thermal Bridges, Energy and Buildings 26, 233-240.

29. Nannei, E., Schenone, C., 1999. Thermal Transients in Buildings: Development and Validation of a Numerical Model, Energy and Buildings, 29, 209 -215.

30. Nimiya, H., Akasaka, H., Obara, S., Itami., K., 1999. Thermal Analysis of 3-Dimensional Heat Bridges Included in Steel Framed Houses: Method of Making Models and Analysis Examples. 6th International Building Simulation Conference, September 13-15, Kyoto Japan.

31. Rock, B.A., Ochs, L.L., 2001. Slab-on-Grade Heating Load Factors for Wood-Framed Buildings, Energy and Buildings 22, 989-998,

32. Salgon, J. J., Neveu, A., 1987. Application of Modal Analysis to Modelling of Thermal Bridges in Buildings, Energy and Buildings, 10(2), 109-120.

33. Schwab, H., Stark, C., Wachtel, J., Ebert, H. P., Fricke, J., 2005. Thermal Bridges in VacuumInsulated Building Facades, Journal of Thermal Envelope and Building Science, 28(4), 345-355.

34. Senkal Sezer, F., Cihan, M. T., Dilmac, S., 2010. Experimental Analysis of the Thermal Behaviour of Mezzanine Floors in Buildings with Cavity Wall Insulation, Scientific Research and Essays, 5 (14), 1925-1934.

35. Senkal Sezer, F., Dilmac, S., Guner, A., 2010. Experimental Study on the Effects of Wall Materials on the Thermal Behavior of
Mezzanine Floors, World Applied Sciences Journal, 8(3), 374-381.

36. Sripada, R. K. L., Angirasa, D., 2001. Simultaneous Heat and Mass Transfer by Naturel Convection Above Upward Facing Horizontal Surfaces, International Journal of Non-Linear Mechanics, 36, 1019-1029.

37. Şenkal Sezer, F., Cihan, M. T., 2012. Dışarıdan Yalıtımlı Binaların Ara Kat Döşemelerinin Isıl Davranışının Deneysel Olarak İncelenmesi, Uludağ Üniversitesi Mühendislik-Mimarlık Fakültesi Dergisi, Cilt:15, Sayı No: 2, 65-72.

37. Van Schijndel, A. W. M., 2003. Modeling and Solving Building Physics Problems with Fem Lab, Building and Environment, 38, 319-327.

38. Y. A., Matrosov, I. N., Butovsky, 1989. U.S.S.R. Experience in Thermal Design of Building Envelopes with Improved Thermal Properties, Energy and Buildings, 14(1), 31-41.

39. Yahia, A.A., Del Barrio, E. P., 1999. Thermal Systems Modelling Via Singular Value Decomposition: Direct and Modular Approach, Applied Mathematical Modelling, 23, 447-468.

40.Zürcher, C., 1985. IR in Building Physics, Infrared Physics, 25(1-2), 497-503. 